\title{
Corrosion behaviour of AZ31magnesium alloy with different grain sizes in simulated biological fluids
}

\section{Alvarez-Lopez ${ }^{1}$, M. D. Pereda ${ }^{2,3}$, J.A. del Valle ${ }^{1}$, M. Fernandez-Lorenzo ${ }^{2,3}$, M.C. Garcia-Alonso ${ }^{1}$, O.A. Ruano ${ }^{1}$, M.L. Escudero ${ }^{1 *}$}

${ }^{1}$ Centro Nacional de Investigaciones Metalúrgicas, CENIM. Consejo Superior de Investigaciones Científicas, CSIC, Avda. Gregorio del Amo 8, 28040 Madrid, España Tf: 0034915538900 ext 247 Fax: 0034915347425

*Corresponding autor: e-mail:escudero@cenim.csic.es (ML Escudero)

${ }^{2}$ Instituto de Investigaciones Fisicoquímicas Teóricas y Aplicadas (INIFTA), Facultad de Ciencias Exactas, Universidad Nacional de La Plata - CONICET, Casilla de Correo 16, Sucursal 4, (1900) La Plata, Argentina

${ }^{3}$ Facultad de Ingeniería, Calle 1 esq. 47, Universidad Nacional de La Plata, (1900) La Plata, Argentina

\begin{abstract}
The comparative study of the corrosion behaviour of the AZ31 magnesium alloy with different grain sizes immersed in simulated body fluids was made in chloride solutions (8g/L) and Phosphate Buffer-containing Solution (PBS). The influence of the immersion time was also analysed. Electrochemical techniques such as the open circuit potential, polarization curves, current transients and electrochemical impedance spectroscopy, complemented with scanning electron microscopy and energy dispersive spectroscopy were used. Immediately after the immersion in the corrosive media the corrosion resistance was similar for both grain sizes of the AZ31 alloy and higher in
\end{abstract}


$\mathrm{NaCl}$ solutions than in PBS. However, this corrosion behaviour was reversed after longer periods of immersion due to the stabilizing of the corrosion products of $\mathrm{MgO}$ and/or $\mathrm{Mg}(\mathrm{OH})_{2}$ with P-containing compounds. These P-compounds contribute to a higher level of protection by hindering the aggressive action of chloride ions. The best corrosion behaviour of the AZ31 alloy was obtained for the finest grain alloy associated with the highest transfer resistance value, after long periods of immersion in PBS.

Keywords: AZ31 Mg alloy; Grain size; Biomaterial; Corrosion; Electrochemical techniques; Aggressive ions

\section{Introduction}

Magnesium is present in high concentration in sea water and is the eighth most abundant element on Earth. It has also excellent specific strength and a low density, only $2 / 3$ that of aluminium, so $\mathrm{Mg}$ and its alloys can be used in many applications including computer parts, mobile phones, aerospace components, handheld tools and so on [1-2]. Magnesium alloys are also potentially useful for bone implants and stent applications due to their low density, inherent biocompatibility and adequate mechanical properties including a fracture toughness higher than that of ceramics [3-6]. Additionally, its elastic modulus (40-45 GPa) is closer to that of human bones (10-40 $\mathrm{GPa}$ ) than other commonly used implant materials. As a result, the stress-shielding phenomena caused by current metallic implants made of stainless steel or titanium alloy can be minimized [7].

Another advantage of magnesium in relation to other metallic implants is the degradability of magnesium alloys which offers the possibility of better physiological 
repair and better reconstruction of vascular compliance with minimum inflammatory response. It has been shown that magnesium apatite precipitates on the surface of the modified pure $\mathrm{Mg}[8,9]$ and osteoblasts respond by degrading magnesium alloys in the guinea pig femur [10]. Magnesium alloys have also shown osteoconductive and osteoinductive properties, thus offering a less invasive repair and temporary support during tissue recovery. The alloys are gradually dissolved or absorbed by the body. In this regard, they are superior to permanent implants, which may cause mismatches in behaviour between the implant and the body as well as physical irritation and chronic inflammatory reactions. As degradable materials, they will not remain as permanent implants in the body nor would need a second surgical operation after the tissue is repaired.

The major drawback of magnesium alloys is that they tend to corrode very quickly in the physiological $\mathrm{pH}(7.4-7.6)$ environment thereby losing their mechanical integrity before the end of the period necessary for bone tissue healing. Therefore, the promising future of $\mathrm{Mg}$ and its alloys is dependent on the corrosion control rate in the body fluids.

Several treatments to protect magnesium against corrosion have been proposed such as magnesium purification [11], fluoride conversion coatings [12], alloying with other elements, anodizing, [1,11,13], etc. Several studies [14-20] have shown that the corrosion behaviour of $\mathrm{Mg}$ alloys is significantly dependent on the microstructure and particularly on the amount and distribution of the intermetallic phases and the grain size. Attempts at improving the corrosion resistance of $\mathrm{Mg}$ alloys by reducing grain size have been proposed by means of laser fusion technology. However, the results obtained by various authors are contradictory [21, 22]. Microcrystallization has been also proposed as a way to improve resistance in chloride media [23]. 
It can therefore be concluded that the reduction of the corrosion rate, by grain size refinement, and the change of this rate as a function of the physiological media is not well established in the case of $\mathrm{Mg}$ alloys. The aim of this work is to evaluate these two effects in an attempt to develop a magnesium alloy with improved corrosion resistance.

\section{Materials and methods}

\subsection{Material}

The AZ31 alloy was received from Magnesium Elektron in the form of a rolled 3 $\mathrm{mm}$ thick sheet in the O-temper condition (annealed at $345{ }^{\circ} \mathrm{C}$ ) and also in the form of a cast ingot. The nominal composition of the AZ31 alloy is: $3 \%$ wt. Al, $1 \%$ wt $\mathrm{Zn}, 0.2$ $\%$ wt $\mathrm{Mn}$ and balance $\mathrm{Mg}$. The alloy was solution-heat treated at $450{ }^{\circ} \mathrm{C}$ for 30 minutes and water quenched. Rolled sheet disks of $10 \mathrm{~mm}$ in diameter were spark machined; these samples were termed Type I.

Slabs, machined out from the ingot were processed by Equal Channel Angular Extrusion (ECAE). The first pass was made at $250^{\circ} \mathrm{C}$ using a square die of $12 \times 12 \mathrm{~mm}$, with an intersection angle of $\Phi=90^{\circ}$ and a plunger speed of $0.1 \mathrm{~mm} / \mathrm{s}$ [24]. The die was heated in situ during the Equal Channel Angular Pressing (ECAP) process and the temperature of the die was maintained stable. The samples were heated successively to $300^{\circ} \mathrm{C}$ and rolled by applying a reduction in thickness from $12 \mathrm{~mm}$ to a final thickness of $3 \mathrm{~mm}$ in one rolling pass. Rapid cooling (quenching) took place during rolling, since the rolling mill was at room temperature. From the rolled slabs, disks of $10 \mathrm{~mm}$ in diameter were machined out; these samples are termed Type II.

\subsection{Microstructural characterization}


The microstructures of the alloy in the different stages of processing were examined by optical microscopy $(\mathrm{OM})$. The sample preparation consisted of grinding on $\mathrm{SiC}$ paper, followed by mechanical polishing with 6 and $1 \mu \mathrm{m}$ diamond paste and short final polishing using colloidal silica. The grain structure was revealed by subsequent etching using a solution of ethanol $(100 \mathrm{ml})$, picric acid $(5 \mathrm{~g})$, acetic acid $(5 \mathrm{ml})$ and water $(10$ $\mathrm{ml})$.

Additionally, microstructural and compositional characterization of the alloy surface was carried out by scanning (SEM) and energy-dispersive X-ray spectroscopy (EDX) microanalysis, after immersion tests in the corrosive media.

\subsection{Corrosive media and electrochemical techniques}

The following solutions were used as electrolytes: a) $\mathrm{NaCl}$ solution: $8 \mathrm{~g} / \mathrm{L}$ and b) Phosphate Buffer Solution (PBS): $0.2 \mathrm{~g} / \mathrm{L} \mathrm{KCl}, 0.2 \mathrm{~g} / \mathrm{L} \mathrm{KH}_{2} \mathrm{PO}_{4}, 8 \mathrm{~g} / \mathrm{L} \mathrm{NaCl}$ and $1.150 \mathrm{~g} / \mathrm{L} \mathrm{Na}_{2} \mathrm{HPO}_{4}$ (anhydrous).

A conventional three electrode electrochemical cell with a platinum wire as a counter electrode and $\mathrm{Ag} / \mathrm{AgCl}$ as a reference electrode was used. The working electrodes were the AZ31 disks. The surface was ground with $\mathrm{SiC}$ abrasive paper of increasing grain size from 600 to 1200 in water and finally polished with $1 \mu \mathrm{m}$ diamond suspension. Finally, AZ31 samples were rinsed ultrasonically in ethanol. Single sweep potentiodynamic polarization curves were performed at $37^{\circ} \mathrm{C}$ at $10 \mathrm{mV} / \mathrm{s}$, between -1.9 $\mathrm{V}$ and different anodic limits. The passivation currents and breakdown potentials $\left(\mathrm{E}_{\mathrm{bd}}\right)$ were determined. At least five polarization curves were generated for each condition 
(Types I and II in PBS and $\mathrm{NaCl}$ solutions). Transient currents were recorded at $-1.60 \mathrm{~V}$ after a potential step between $-1.9 \mathrm{~V}$ and $-1.6 \mathrm{~V}$.

Electrochemical Impedance Spectroscopy (EIS) was carried out after 2 hours, 24 hours and 2, 3, 4 and 6 days testing time. Before the EIS measurements, the corrosion potential was registered over 10 minutes until the potential was stabilised. The EIS experiments were performed at the corrosion potential by applying a sinusoidal wave of $10 \mathrm{mV}$ in amplitude in a frequency range from $2 \times 10^{4}$ to $10^{-2} \mathrm{~Hz}$ spaced logarithmically (five per decade). A 1280 Solartron frequency response analyzer was used to perform the electrochemical tests.

The EIS results were analysed by fitting the experimental impedance data with different equivalent circuit models. The equivalent circuit parameters were calculated by fitting the impedance function to the measured spectra by a Non-Linear LeastSquares program (NLLS program) for all the frequencies measured. The criteria used in estimating the quality of the fitting were evaluated firstly with the lower chi-square value, and secondly with the lower estimative errors (in \%) for all the components.

\section{Results}

\subsection{Microstructural characterization}

The microstructure of Type I and Type II AZ31 alloy is shown in Figure 1(a) and 1(b) respectively. True grain sizes were measured by the linear intercept method using a correction factor of 1.74. The mean grain sizes were $\mathrm{d}=25.7$ and $4.5 \mu \mathrm{m}$ for Type I and Type II samples respectively. In both, Type I and II samples, some particles of Mn-rich phase $\left(\mathrm{Al}_{6} \mathrm{Mn}\right)$ still remained present in the microstructure after processing. Their volume fraction was estimated by image analysis to be close to $3 \times 10^{-3}$. 


\subsection{Initial stages of corrosion}

Polarization curves recorded immediately after the immersion of Type I AZ31 samples in $\mathrm{NaCl}$ and PBS are shown in Figure 2. Higher cathodic current and slightly higher breakdown potential is observed for the $\mathrm{NaCl}$ than for the PBS solutions. The curves corresponding to Type II samples are depicted in Figure 3. The breakdown potential measured in both solutions is similar for these samples.

The transient current recorded at a $-1.60 \mathrm{~V}$ in $\mathrm{NaCl}$ for Type II AZ31 alloy is shown in Figure 4. The figure reveals that initially the current decreases, remains stable for a few seconds and then increases rapidly. Conversely, in the case of PBS, after the initial decrease, the current increases immediately.

Figures 5 and 6 show the Nyquist impedance plots in $\mathrm{NaCl}$ and PBS, after 2 hours of immersion, for Type I and II samples, respectively. In the impedance plot for Type I samples (Figure 5), a depressed semicircle at high frequencies and an inductive loop at low frequencies are observed, independently of the medium, PBS or $\mathrm{NaCl}$. In the impedance plot for Type II (Figure 6), the capacitive arc is followed by a possible second arc that could be influenced by a diffusion process. Considering that the kinetics information, referring to the corrosion behaviour is estimated from the capacitive arc obtained in the high frequency (HF) and medium frequency (MF) ranges, the analysis of the impedance data will be focused on this part of the spectra. By comparing the diameter of the capacitive arcs, obtained in Figures 5 and 6, higher diameters for samples immersed in $\mathrm{NaCl}$ than those immersed in PBS were found, thus showing a higher corrosion resistance in $\mathrm{NaCl}$ medium. 
This fact is corroborated by the examination of the surface by optical and electron microscopy. Figure 7 shows micrographs of the formation of a pit after $1 \mathrm{~h}$ immersion in PBS for Type II samples. The optical micrograph, Figure 7a, shows that the surface is covered by a dark protective layer with white circles inside. Figure $7 \mathrm{~b}$ shows a pit, around which, precipitation has taken place. The mapping of the elements detected in this area can be seen in Figures $7 \mathrm{c}-7 \mathrm{j}$. The small pit is formed close to the intermetallic AlMn deposit (Figures $7 \mathrm{~b}, \mathrm{~d}$, and e). High $\mathrm{P}$ signals around the pits are observed in Figure $7 \mathrm{~g}$. However, after $1 \mathrm{~h}$ immersion, Type II samples did not show the formation of pits in $\mathrm{NaCl}$. This observation reveals that the phosphate included in the PBS initially accelerates the corrosion of the AZ31 alloy.

\subsection{Evolution over time of the corrosion kinetics}

Figure 8 shows the impedance plots for Types I and II in PBS after 6 days immersion. A higher diameter for Type II samples is obtained.

Analysis of experimental impedance data shows that more than one time constant is necessary to describe the corrosion behaviour since the impedance data do not produce a simple semicircle in the capacitive half plane. Figure 9 shows the equivalent circuits used to simulate the impedance data of the AZ31 alloy of both Types of samples, I and II, immersed in $\mathrm{NaCl}$ or PBS solutions. The HF-MF arc was simulated by using a simple Randles circuit (Figure 9a) consisting of the electrolyte resistance, Rs, in series with a Constant Phase Element, CPE, simulating a non-ideal behaviour of the capacitor due to the sum of the oxide layer capacitance and the double-layer capacitance, in parallel with the transfer charge resistance, R1. In order to simulate the low frequency (LF) range, a second branch is added in the Randles circuit (Figure 9b), in which an 
inductive element L1, appears to describe the corrosion behaviour at low frequencies. The fitting of the first arc (HF-MF range) gives valuable information about the corrosion kinetics of the AZ31 alloy. Table 1 shows fitting values obtained with the equivalent circuits and experimental values obtained from the impedance data. The Table summarises the values obtained for both Types of samples, I and II, in both corrosive media at two hours and after 6 days immersion. The increase of Rs over time is higher in PBS than in $\mathrm{NaCl}$ solutions and this occurs independently of the type of sample. In addition, an improvement in R1 over time for Type I samples immersed in $\mathrm{NaCl}$ and PBS solutions is seen. The same is observed in Type II samples but the effect is more pronounced in PBS. On the other hand, Type II samples immersed in $\mathrm{NaCl}$ show that the capacitance slightly increases whereas in PBS the capacitance is nearly constant.

\section{Discussion}

The application of $\mathrm{Mg}$ and its alloys as biomaterial for temporal implants in the form of plates and screws would be effective when the corrosion kinetics are understood and controlled in body fluids. A possible route to reduce the corrosion rate could be the reduction of the grain size. With this goal in sight, the research developed in this work consisted mainly in the evaluation of the corrosion behaviour of Type I and Type II AZ31 magnesium alloy of different grain size in two electrolyte media. The Al present in the AZ31 alloy, 3\% in weight, increases the corrosion resistance of $\mathrm{Mg}$ by stabilizing the passive layer $[14,25-26]$. Larger amounts of $\mathrm{Al}$ are not recommended since aluminium ions can easily combine with inorganic phosphates, leading to a lack of phosphate in the human body and inducing dementia [11,27]. Furthermore, the 
relatively small amount of $\mathrm{Al}$ ensures the presence of only one phase in the alloy thus avoiding second phases that may be detrimental for the corrosion behaviour. The $\mathrm{Zn}$ content in the alloy makes for satisfactory mechanical properties and can at the same time be tolerated in the human body. So this $\mathrm{Zn}$ content increases the corrosion resistance and retards the biodegradation of magnesium alloys $[11,14]$.

Type I AZ31 samples are in the O-temper condition corresponding to the annealed and recrystallized microstructure. The processing route used to obtain Type II samples leads to a fine grain size, $4.5 \mu \mathrm{m}$, which is similar to that obtained with severe plastic deformation techniques. The processing temperature of the rolling pass, $300^{\circ} \mathrm{C}$, is above the solvus temperature for aluminum in this alloy. Therefore, the $\mathrm{Al}$ is in solid solution during rolling. Due to the rapid cooling that takes place after rolling and since the rolling mill is at room temperature, no precipitation of the beta-phase, $\mathrm{Mg}_{17} \mathrm{Al}_{12}$, takes place. Compositional maps obtained by EDX show that $\mathrm{Zn}$ and Al are homogeneously distributed in the Mg matrix in both Types I and II samples. After the processing route [28], some particles of Mn-rich phase $\left(\mathrm{Al}_{6} \mathrm{Mn}\right)$ still remained present in the microstructure as can be seen in Figure 7.

Results for the initial stages of immersion show that the corrosion behaviour of Types I and II samples depends on the testing media, $\mathrm{NaCl}$ or PBS. The polarization curves obtained in $8 \mathrm{~g} / 1 \mathrm{NaCl}$ (Figures 2 and 3) show a pseudo-passive region followed by a sharp current increase at the breakdown potential due to the action of chloride. Correspondingly, the current transients for Type II (Figure 4) and Type I (not shown) recorded at $-1.60 \mathrm{~V}$ in $\mathrm{NaCl}$ show that the current decreases initially, probably due to the formation of the pseudopassive layer of $\mathrm{Mg}(\mathrm{OH})_{2}$. The current remains low during $20 \mathrm{~s}$ for Type II in $\mathrm{NaCl}$ and then increases due to the localised corrosion induced by chloride ions. Later, pitting spreads laterally. The current "plateau" is not observed in 
PBS. In this case, the current increases immediately because the high $\mathrm{pH}$ needed for $\mathrm{Mg}(\mathrm{OH})_{2}$ formation is not reached. In the same way, after a short immersion period (30 min) pits are only observed in PBS. These results agree with the transfer resistance, R1 values (Table 1 at 2 hours) obtained from impedance diagrams (Figures 5 and 6) which show a higher value in $\mathrm{NaCl}$ than in PBS. This different behaviour is attributed to the electrochemically dissolution of $\mathrm{Mg}$ in the surrounding areas (anodic zones) of the intermetallic inclusions (cathodic areas).

The kinetics data of the corrosion behaviour of the samples are shown in Table 1 that summarises the charge transfer resistance, R1, values obtained from the HF-MF capacitive arc at two hours testing. The diameter of the first capacitive arc at high frequency (Figures 5 and 6) can be ascribed to the R1 value that includes the resistance of the passive film and/or the layer of corrosion products [29]. The value of the semicircle diameter closely corresponds to the R1 value, only if the resistance of the passive film is much lower than the charge transfer resistance [29]. The capacitance values obtained at the maximum of the semicircle are 7.8 and $12.6 \mu \mathrm{F} / \mathrm{cm}^{2}$ in $\mathrm{NaCl}$ and PBS respectively, for the Type I samples (similar values are also obtained for Type II samples). These values are lower than those obtained for the electrochemical double layer which are about $20-50 \mu \mathrm{F} / \mathrm{cm}^{2}[29]$.

The best electrochemical results at the initial stages, obtained in samples immersed in $\mathrm{NaCl}$ with respect to the PBS medium, can be attributed to the electrochemical dissolution of $\mathrm{Mg}$ thus favouring the production of $\mathrm{OH}^{-}$ions as a result of the hydrogen gas formation in the cathodic reaction. The presence of $\mathrm{OH}^{-}$ions causes an increase of $\mathrm{pH}$ in the medium and facilitates the formation and precipitation of $\mathrm{MgO}$ and/or $\mathrm{Mg}(\mathrm{OH})_{2}$ as corrosion products. In the case of AZ31 samples immersed in PBS, the phosphate ions $\left(\left(\mathrm{HPO}_{4}\right)^{2-}\right)$ possibly capture the $\mathrm{OH}^{-}$that is produced by the cathodic 
reaction and consequently the high alkaline $\mathrm{pH}$ (that favours the massive precipitation of $\mathrm{Mg}$ hydroxide) cannot be reached. On the other hand, the phosphate precipitation hinders the action of chloride and $\mathrm{Mg}$ dissolution is slower.

The change of $\mathrm{E}_{\text {corr }}$ over time (Figure 10) is more important in Type II and is probably related to its higher surface reactivity being more evident during the first hours. The most marked differences between Type I and Type II samples could be observed in the EIS measurements. After the first capacitive arc that appears in both samples, Type I and II, (Figures 5 and 6) the shape of the impedance diagrams is different. The Type I samples show an inductive arc in both media, $\mathrm{NaCl}$ and PBS (Figure 5). The Type II samples show a possible second arc (Figure 6).

The inductive loop (Type I) is assumed to be due to the formation of the $\operatorname{Mg}(\mathrm{OH})_{2}$ and/or $\mathrm{MgO}$, already mentioned, and to the coverage due to an adsorbed intermediate (probably $\mathrm{Mg}(\mathrm{OH})^{+}$ads ) or $\mathrm{Mg}(\mathrm{OH})_{2}$ [14,29]. The presence of this loop has been attributed, in the bibliography, to pitting processes [30] and also to the formation and precipitation of a salt film [31]. In our case, a discrete thin film is formed in the air and pitting corrosion may easily be initiated in the presence of chloride ions. It is the dissolution of this film that yields to the formation of corrosion products on the electrode surface. This behaviour agrees with the observation of other authors on the same alloy, AZ31 immersed in $3.0 \mathrm{wt} \%$ of $\mathrm{NaCl}[1,32]$.

The second arc observed for Type II samples (Figure 6) in both solutions, $\mathrm{NaCl}$ and PBS, could be attributed to mass transport in the solid phase due to the growth of the corrosion product layer [14], facilitated by the finer grain size. This diffusion process slows down the corrosion reaction, giving rise to an increase in the corrosion resistance, i.e., to a decrease of the corrosion rate. 
The corrosion behaviour at initial stages is reversed when immersion time is increased and after six days the corrosion resistance is improved. R1 increases its value for samples immersed in PBS with respect to those immersed in $\mathrm{NaCl}$ (Table 1). This evolution of the corrosion behaviour with the immersion time is due to the accumulation of corrosion products, forming a layer that promotes a diffusive control of the corrosion process of the samples. After 6 days testing in $\mathrm{PBS}$, the released $\mathrm{PO}_{4}{ }^{-}$coprecipitates as Mg phosphate (Figure 7) together with the Mg oxide and hydroxide that is formed. The presence of phosphates has been detected, by Fourier Transform Infrared FTIR spectroscopy [33]. The increase of R1 over time could be related to the formation of a mixed layer that is increasingly thick and more compact with time hindering the diffusion of ions, particularly in case of Type II.

Summarizing, the best corrosion behaviour of the AZ31 is obtained for the finest grain alloy, Type II. This good result is attributed to a more negative corrosion potential than that of Tipe I, giving rise to a fast electrochemical reaction and the formation of a layer of corrosion products, which protects from the diffusion of aggressive ions to the electrode surface. Immediately after the immersion, the corrosion resistance is higher in $\mathrm{NaCl}$ solution than in PBS, but this behaviour is reversed after longer periods of immersion due to the stabilization of the layer by P-containing compounds. These compounds contribute to a higher protection than that of the magnesium hydroxide formed in $\mathrm{NaCl}$ solution because they hinder the detrimental action of chloride ions.

\section{Conclusions}


1. At initial stages, pits are associated with the presence of AlMn intermetallics. The monophasic AZ31 alloy shows pitting corrosion that spreads laterally for both Types of samples.

2. For short periods, the initiation of localized corrosion occurs earlier in PBS than in $\mathrm{NaCl}$. However, the precipitation of P-containing salts in PBS decreases the corrosion rate over time for both Types of samples.

3. The best performance corresponds to the AZ31 alloy with the finest grain size in PBS. It reveals the lower initial corrosion potential and higher charge transfer resistance values at long immersion periods. This could be related to the presence of a mixed compact layer of P-containing compounds, together with magnesium hydroxide, that promote protection against the action of chloride ions.

\section{Acknowledgements}

The authors acknowledge the Ministerio de Educación y Ciencia, Spain, for financial support by projects MAT 2006-02672 and MAT2008-06719-C03-01.

DP and MFLM acknowledge the financial support by ANPCyT (PICT 05-33225, PICT 05-32906), UNLP (11/I129), and CONICET (PIP 6075).

\section{References}

[1] Wu CS, Zhang Z, Cao FH, Zhang LJ, Zhang JQ, Cao CN. Study on the anodizing of AZ31 magnesium alloys in alkaline borate solutions. Appl Surf Sci 2007; 253: 38933898. 
[2] Gray JE, Luan B. Protective coatings on magnesium and its alloys-a critical review. J Alloy Compd 2002; 336: 88-113.

[3] Heublein B, Rohde R, Kaese V, Niemeyer M, Hartung W, Haverich A. Biocorrosion of magnesium alloys: a new principle in cardiovascular implant technology. Heart 2003;89:651-656.

[4] Zartner P, Cesnjevar R, Singer H, Weyand M. First successful implantation of a biodegradable metal stent into the left pulmonary artery of a preterm baby. Catheter Cardio Int 2005; 66: 590-594.

[5] Staiger M, Pietak A, Huadmai J, Dias G. Magnesium and its alloys as orthopedic biomaterials: A review. Biomaterials 2006;27:1728-1734.

[6] Mani G, Feldman MD, Patel D, Agrawal CM. Coronary stents: A materials perspective. Biomaterials 2007; 28: 1689-1710.

[7] Xu L, Yu G, Zhang E, Pan F, Yang K. In vivo corrosion behavior of Mg-Mn-Zn alloy for bone implant application. J Biomed Mater Res, Part A 2007; 83A: 703-711. [8] Kuwahara H, Al-Abdullat Y, Mazaki N, Tsutsumi S, Aizawa T. Precipitation of magnesium apatite on pure magnesium surface during immersing in Hank's solution. Mater Trans 2001; 42: 1317-1321.

[9] Al-Abdullat Y, Tsutsumi S, Nakajima N, Ohta M, Kuwahara H, Ikeuchi K. Surface modification of magnesium by $\mathrm{NaHCO}_{3}$ and corrosion behaviour in Hank's solution for new biomaterial applications. Mater Trans 2001; 42: 1777-1780.

[10] Witte F, Kaese V, Haferkamp H, Switzer E, Meyer-Linderberg A, Wirth CJ, Windhagen $\mathrm{H}$. In vivo corrosion of four magnesium alloys and the associated bone response. Biomaterials 2005; 26: 3557-3563. 
[11] Song G. Control of biodegradation of biocompatable magnesium alloys. Corros Sci 2007; 49: 1696-1701.

[12] Chiu KY, Wong MH, Cheng FT, Man HC. Characterization and corrosion studies of fluoride conversion coating on degradable Mg implants. Surf Coat Tech 2007; 202:590-598.

[13] Zhang Y, Yan C, Wang F, Li W. Electrochemical behaviour of anodized Mg alloy AZ91D in chloride containing aqueous solution. Corros Sci 2005; 47: 2816-2831.

[14] Baril G, Blanc C, Pébère N. AC impedance spectroscopy in characterizing timedependent corrosion of AZ91 and AM50 magnesium alloys. J Electrochem Soc 2001; 148: B489-B496.

[15] Lunder $\mathrm{O}$, Lein JE, Aune $\mathrm{TKr}$, Nisancioglu K. Role of $\mathrm{Mg}_{17} \mathrm{Al}_{12}$ phase in the corrosion of Mg alloy AZ91. Corrosion 1989; 45: 741-748.

[16] Nisancioglu K, Lunder O, Aune TKr, in Proceedings of the 47th Annual World Magnesium Conference, The International Magnesium Association, 1990 p.47.

[17] Song G, Atrens A, Wu X, Zhang B. Corrosion behaviour of AZ21, AZ501 and AZ91 in sodium chloride. Corros Sci 1998; 40: 1769-1791.

[18] Song G, Atrens A, Dargusch M. Influence of microstructure on the corrosion of diecast AZ91D. Corros Sci 1999; 41: 249-273.

[19] Uzan P, Frumin N, Eliezer D, Aghion E, in Proceedings of the Second Israeli International Conference on Magnesium Science and Technology, 2000. p. 385-391. [20] Ambat R, Aung NN, Zhou W. Evaluation of microstructural effects on corrosion behaviour of AZ91D magnesium alloy. Corros Sci 2000; 42: 1433-1455. 
[21] Abbas G, Liu Z, Skeldon P. Corrosion behaviour of laser-melted magnesium alloys. Appl Surf Sci 2005; 247: 347-353.

[22] Dubé D, Fiset M, Couture A, Nakatsugawa I. Characterization and performance of laser melted AZ91D and AM60B. Mat Sci Eng A-Struct 2001; 299: 38-45.

[23] Li Y, Zhang T, Wang F. Effect of microcrystallization on corrosion resistance of AZ91D alloy. Electrochim Acta 2006; 51: 2845-2850.

[24] del Valle JA, Carreño F, Ruano OA. Influence of texture and grain size on work hardening and ductility in magnesium-based alloys processed by ECAP and rolling. Acta Mater 2006;54:4247-4259.

[25] Nordlien JH, Nisancioglu K, Ono S, Masuko N. Morphology and structure of oxide films formed on MgAl alloys by exposure to air and water. J Electrochem Soc $1996 ; 143: 2564-2572$.

[26] Nordlien JH, Nisancioglu K, Ono S, Masuko N. Morphology and structure of water-formed oxides on ternary MgAl alloys. J Electrochem Soc 1997; 144: 461-466.

[27] Lucey TD, Venugopal B, Metal Toxicity in Mammals, Plenum Press, New York 1977.

[28] Pérez-Prado MT, del Valle JA, Contreras JM, Ruano OA. Microstructural evolution during large strain hot rolling of an AM60 Mg alloy. Scripta Mater 2004; 50: $661-665$.

[29] Pebere N, Riera C, Dabosi F. Investigation of magnesium corrosion in aerated sodium sulfate solution by electrochemical impedance spectroscopy. Electrochim Acta 1990; 35: 555-561. 
[30] Metikoš-Huković M, Babić R, Grubač Z, Brinić S. Impedance spectroscopic study of aluminium and Al-alloys in acid solution: inhibitory action of nitrogen containing compounds. J Appl Electrochem 1994; 24: 772-778.

[31] Breslin CB, Rudd AL. Activation of pure Al in an indium-containing electrolyte-an electrochemical noise and impedance study. Corros Sci 2000; 42: 1023-1039.

[32] Song G, Atrens A, John D, Wu X, Nairn J. The anodic dissolution of magnesium in chloride and sulphate solutions. Corros Sci 1997; 39: 1981-2004.

[33] Xin Y, Huo K, Tao H, Tang G, Chu PK. Influence of aggressive ions on the degradation behavior of biomedical magnesium alloy in physiological environment. Acta Biomater 2008; 4: 2008-2015. 


\section{FIGURE CAPTIONS}

Figure 1.- Microstructure of AZ31 samples: Type I (a) and Type II (b).

Figure 2.- Potentiodynamic polarization curves of Type I AZ31 alloy at $1 \mathrm{mV} / \mathrm{s}$ in $\mathrm{NaCl}$ and PBS.

Figure 3.- Potentiodynamic polarization curves of Type II AZ31 alloy at $1 \mathrm{mV} / \mathrm{s}$ in $\mathrm{NaCl}$ and $\mathrm{PBS}$.

Figure 4.- Transient currents recorded at $-1.60 \mathrm{~V}_{(\mathrm{SCE})}$ in Type II AZ31 alloy in $\mathrm{NaCl}$ and PBS.

Figure 5.- Nyquist plots of Type I AZ31 alloy in $\mathrm{NaCl}$ and PBS for two hours immersion time.

Figure 6.- Nyquist plots of Type II AZ31 alloy in $\mathrm{NaCl}$ and PBS for two hours immersion time.

Figure 7.- Micrographs of the formation of a small pit after $30 \mathrm{~min}$ of immersion for Type II AZ31 alloy in PBS. a) optical microscopy, b) electron secondary image, c) mapping of $\mathrm{Mg}$, d) mapping of $\mathrm{Al}$, e) mapping of $\mathrm{Mn}, \mathrm{f}$ ) mapping of $\mathrm{Fe}$, g) mapping of $\mathrm{P}, \mathrm{h}$ ) mapping of $\mathrm{Cl}, \mathrm{i})$ mapping of $\mathrm{Na}$ and $\mathrm{j}$ ) mapping of $\mathrm{O}$. 
Figure 8.- Nyquist plots of Type I and Type II AZ31 alloys in PBS solution for six days immersion time .

Figure 9.- Equivalent circuits. Rs is the electrolyte resistance; CPE1 is the oxide film capacitance and the double layer capacitance; R1 is the charge transfer resistance and the oxide film resistance; $\mathrm{L} 1$ is the inductive element.

Figure 10.- Corrosion potential, $\mathrm{E}_{\text {corr, }}$ of Type I and Type II AZ31 alloy in PBS over immersion time.

\section{TABLE CAPTION}

Table 1.- Results obtained from the impedance diagrams for the Type I and II AZ31 alloys in $\mathrm{NaCl}$ and PBS over immersion time and fitted data of the equivalents circuits of Figure 9. 

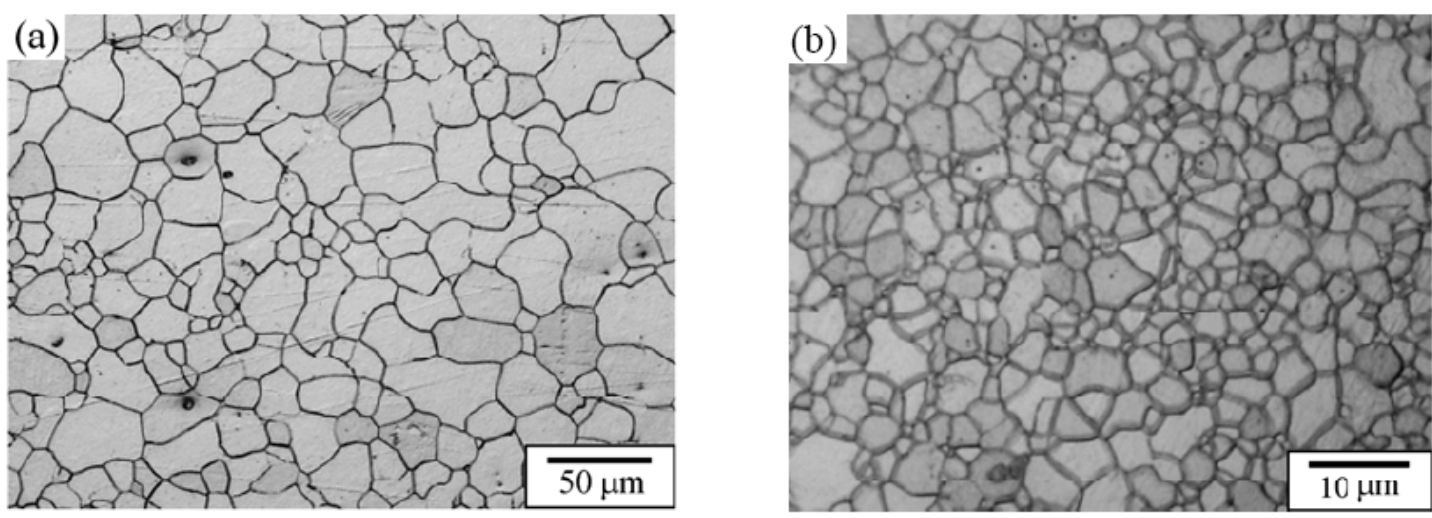

Figure 1. Microstructure of AZ31 samples: Type I (a) and Type II (b).

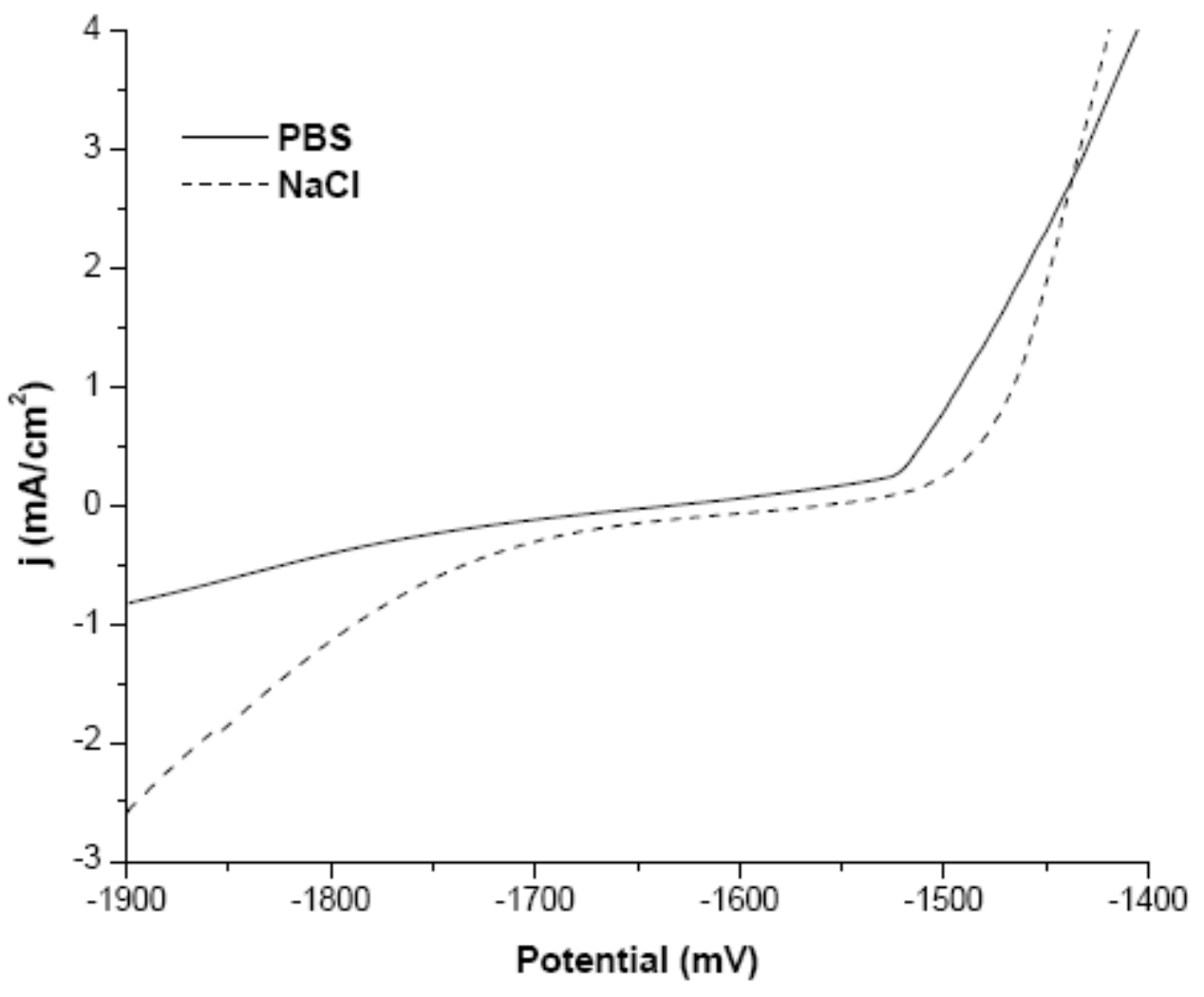

Figure 2. Potentiodynamic polarization curves of Type I AZ31 alloy at $1 \mathrm{mV} / \mathrm{s}$ in $\mathrm{NaCl}$ and PBS . 


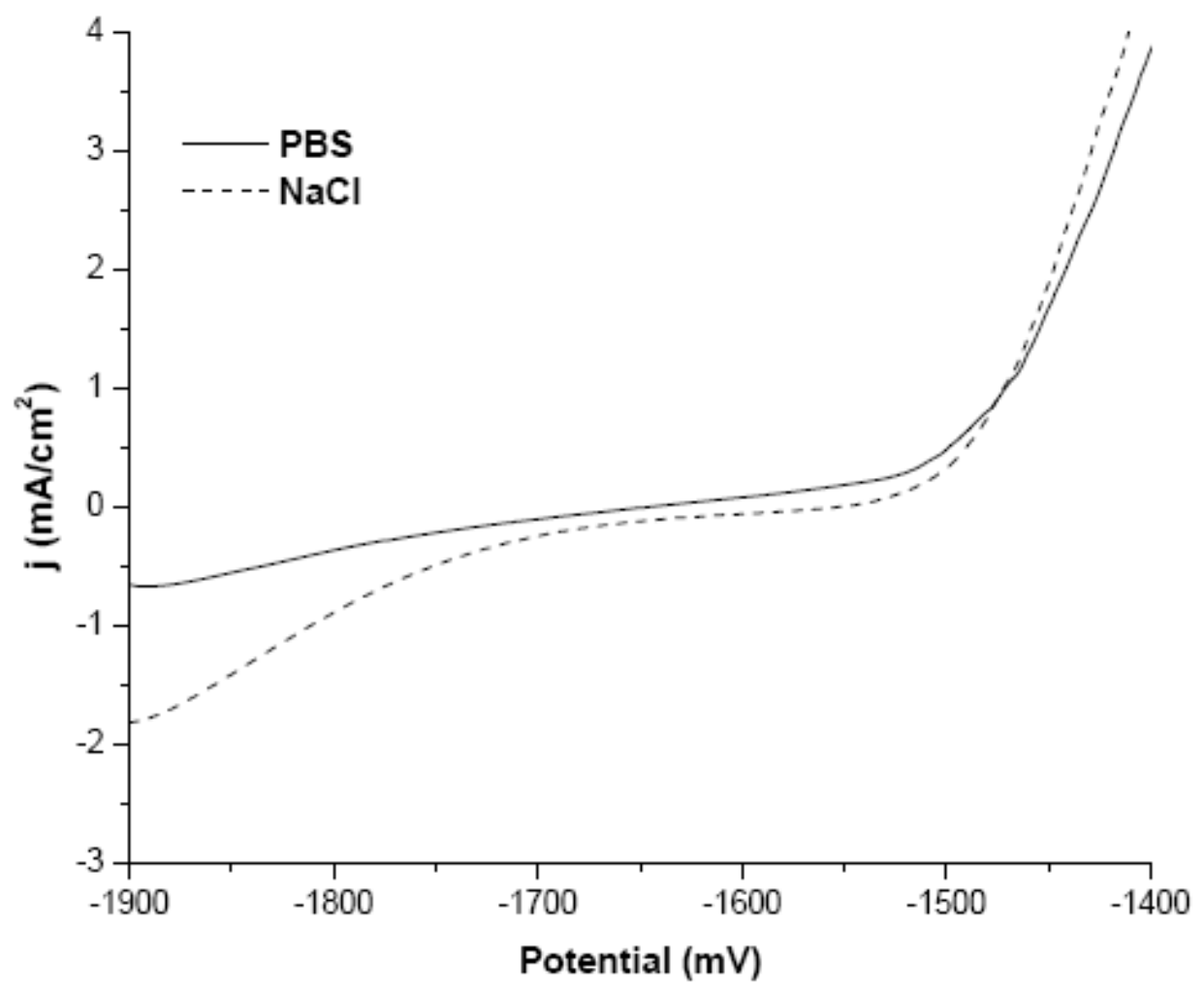

Figure 3. Potentiodynamic polarization curves of Type II AZ31 alloy at $1 \mathrm{mV} / \mathrm{s}$ in $\mathrm{NaCl}$ and PBS. 


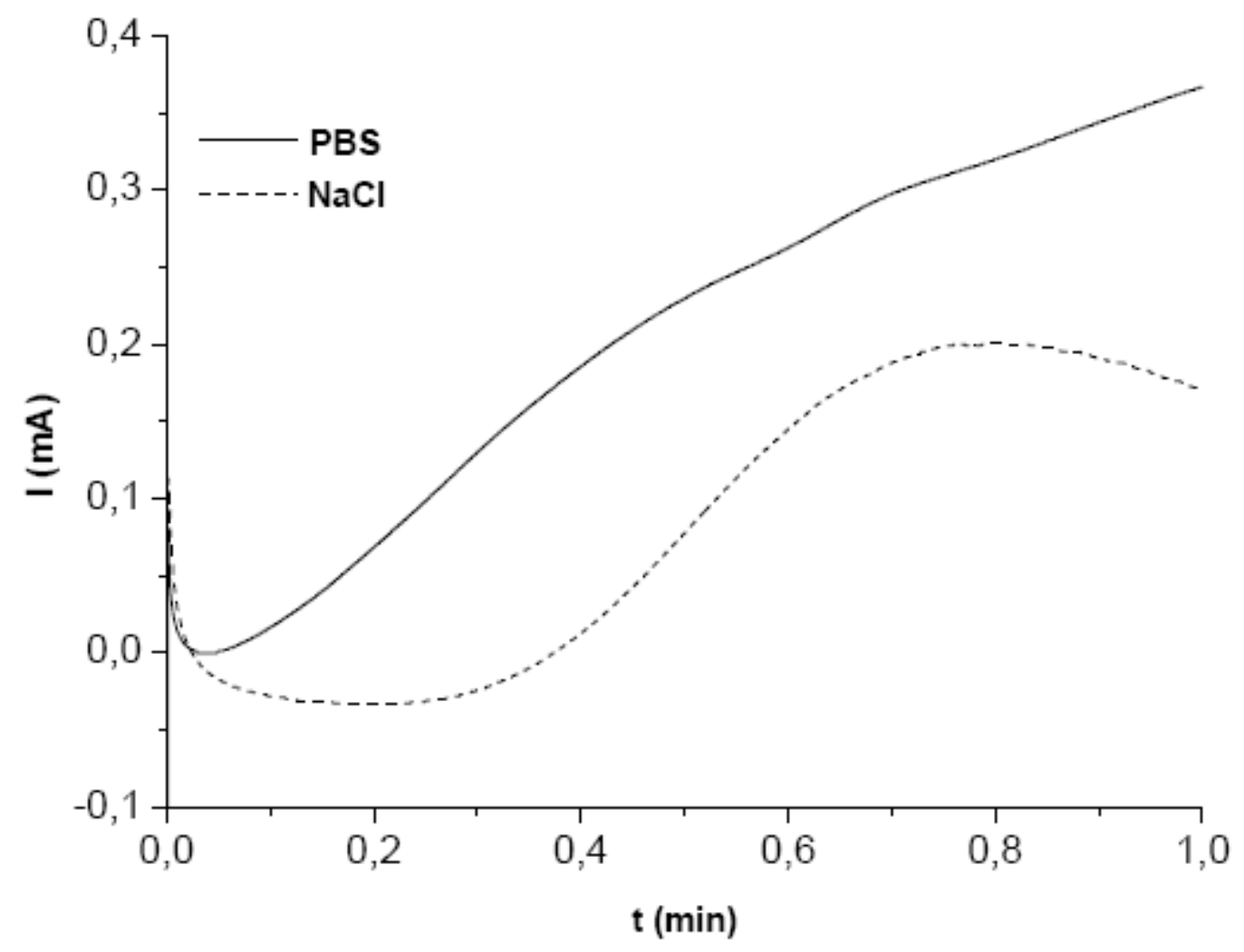

Figure 4. Transient currents recorded at $-1.60 \mathrm{~V}$ (SCE) in Type II AZ31 alloy in NaCl and PBS. 


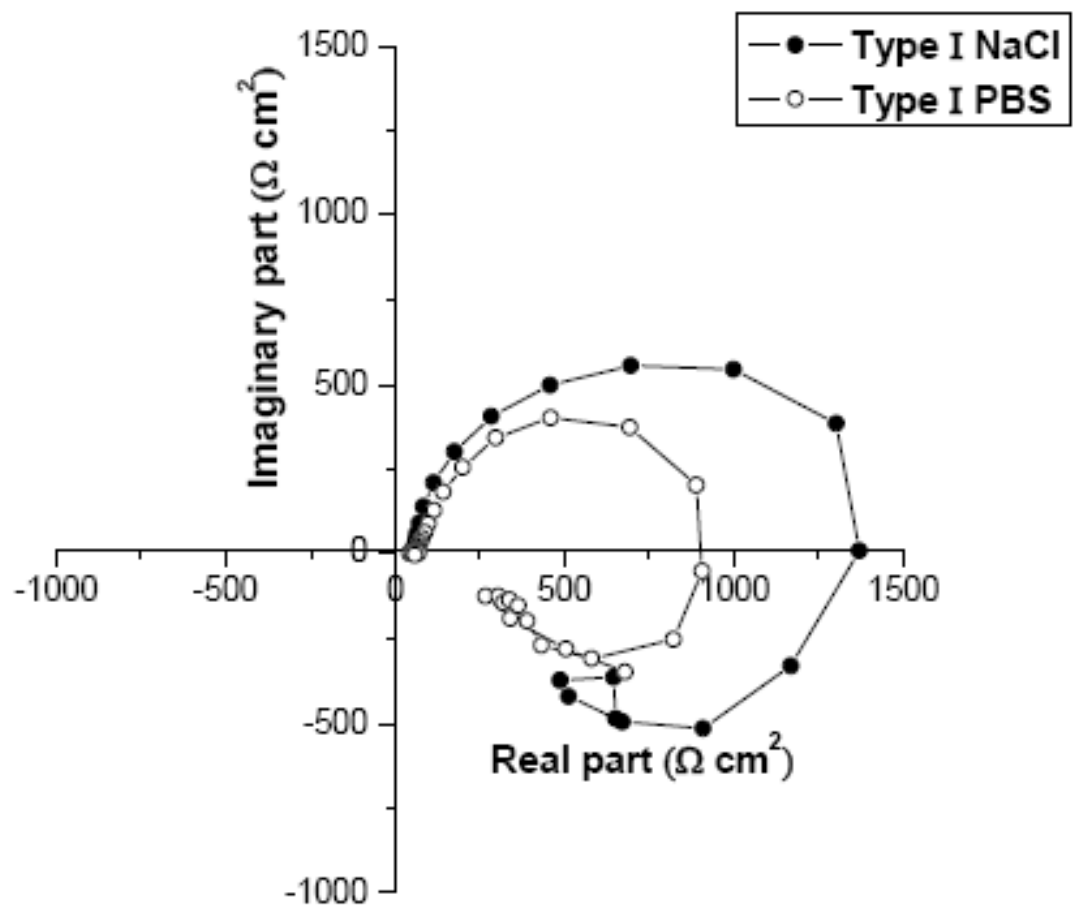

Figure 5. Nyquist plots of Type I AZ31 alloy in $\mathrm{NaCl}$ and PBS for two hours immersion time.

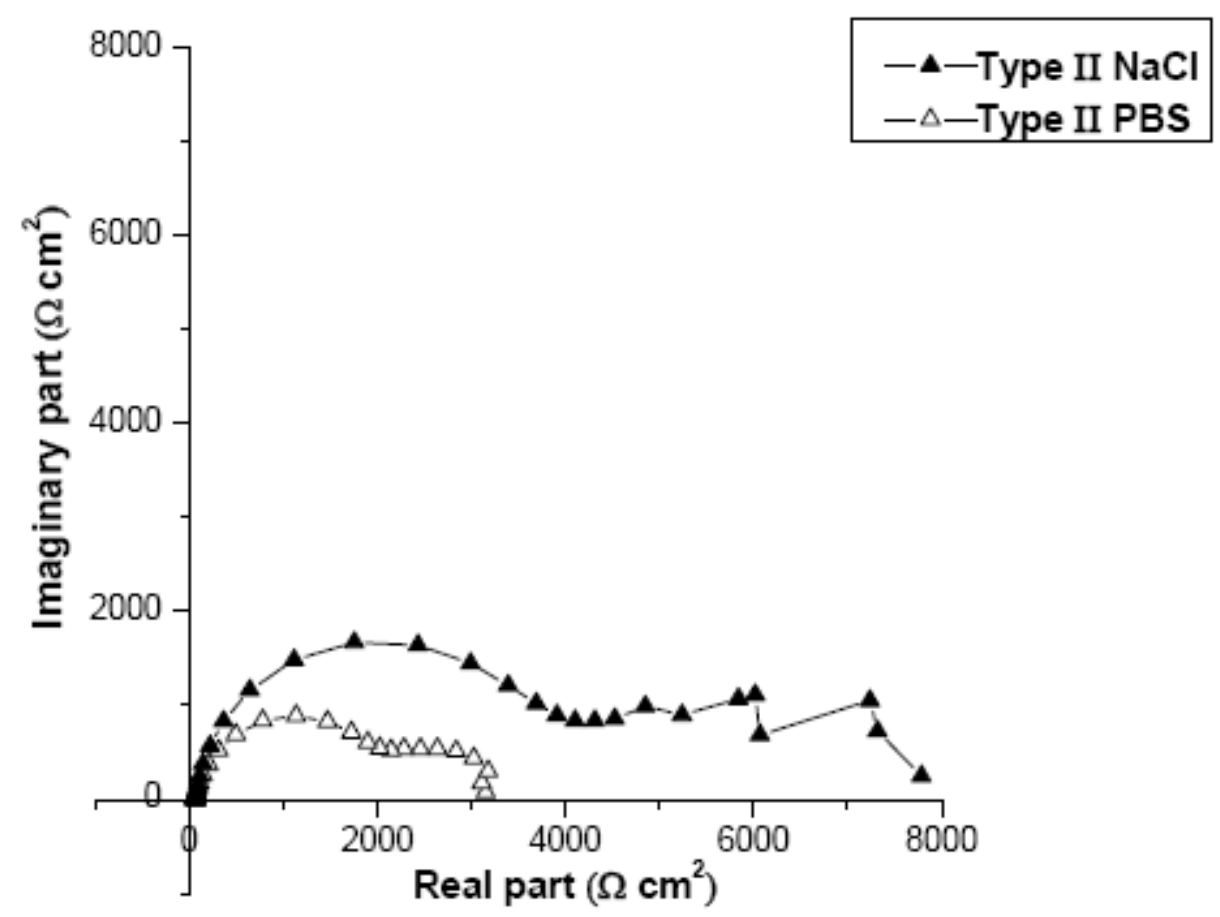

Figure 6. Nyquist plots of Type II AZ31 alloy in $\mathrm{NaCl}$ and PBS for two hours immersion time. 
(a)

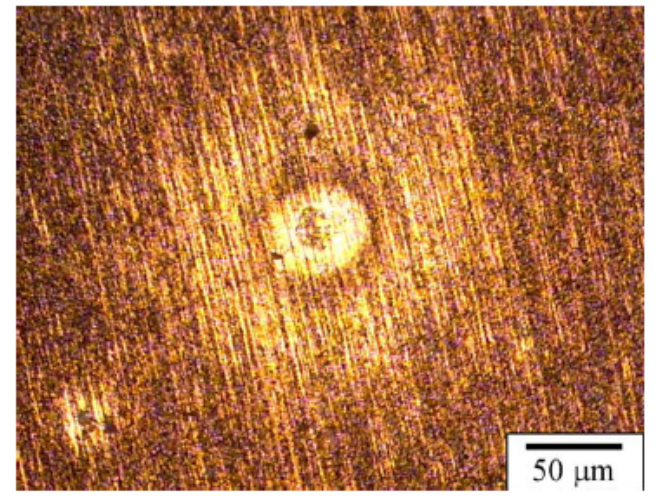

(c)

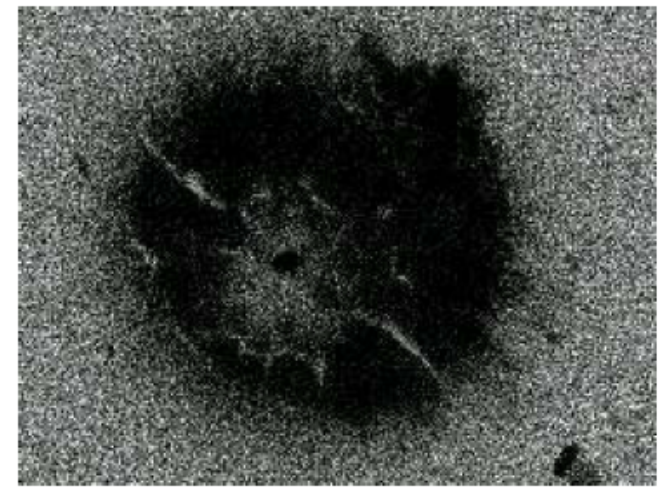

(e)

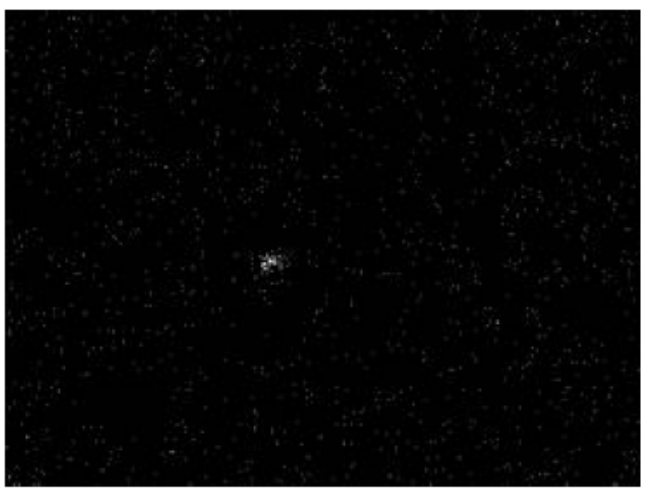

(g)

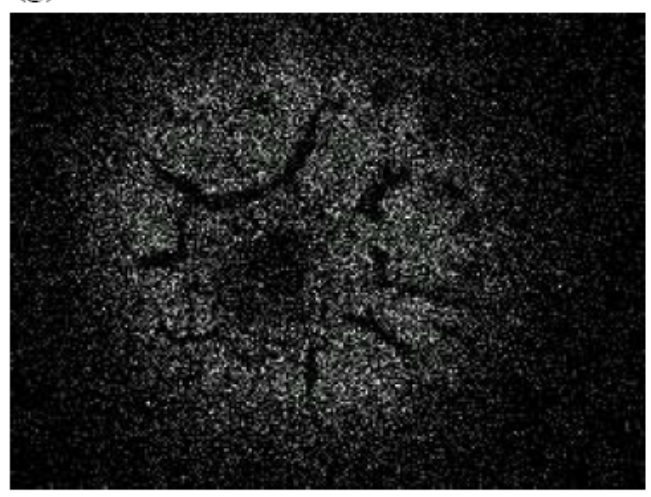

(b)

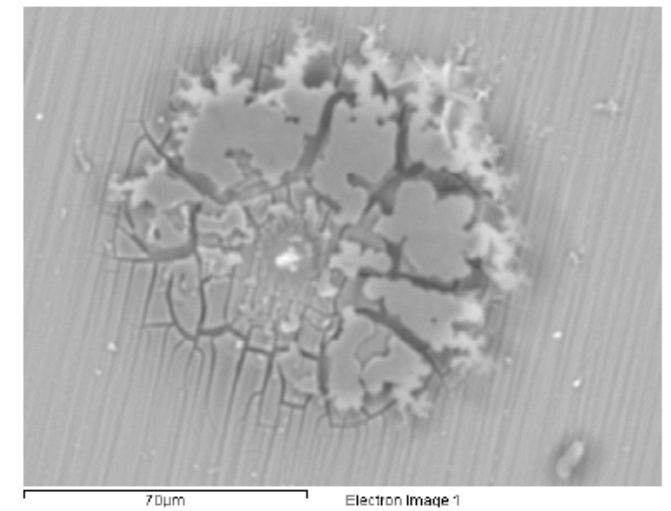

(d)

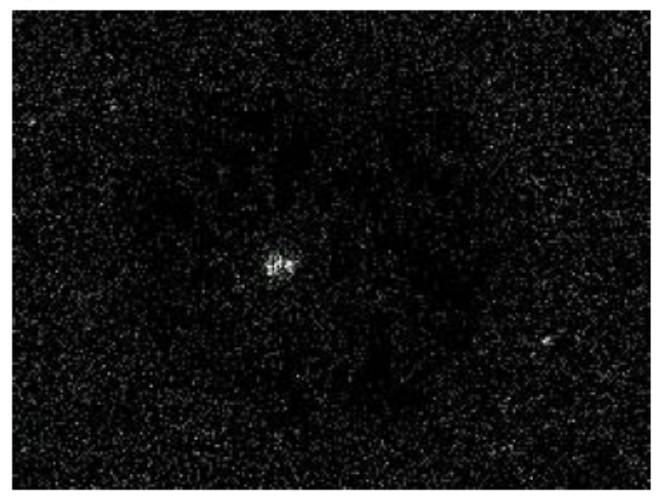

(f)

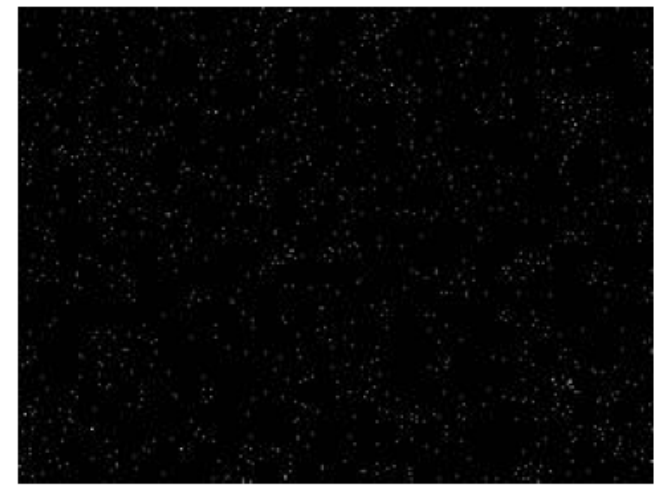

(h)

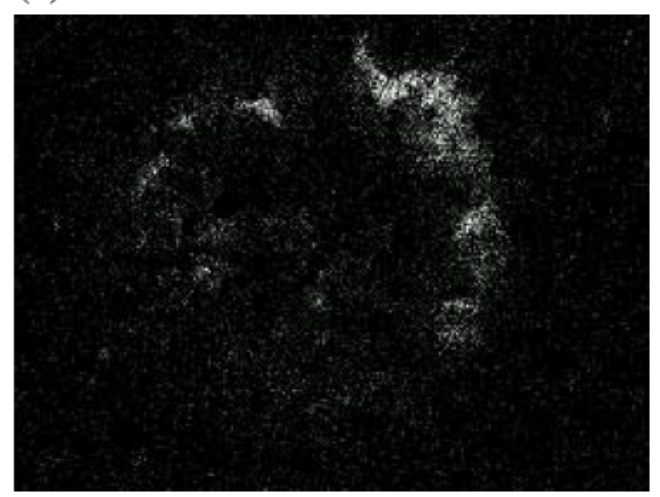


(i)

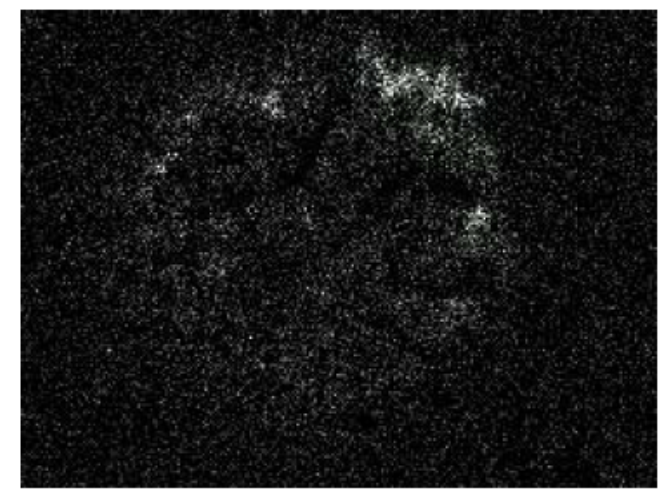

(j)

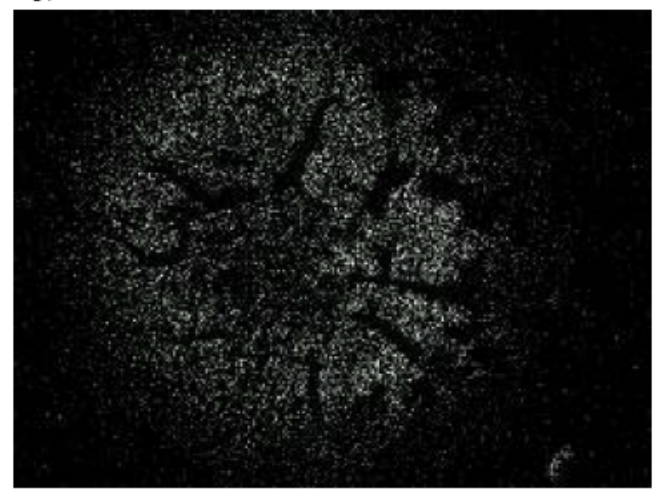

Figure 7. Micrographs of the formation of a small pit after 30 min of immersion for Type II AZ31 alloy in PBS. a) optical microscopy, b) electron secondary image, c) mapping of $\mathrm{Mg}$, d) mapping of $\mathrm{Al}, \mathrm{e}$ ) mapping of $\mathrm{Mn}, \mathrm{f}$ ) mapping of $\mathrm{Fe}, \mathrm{g}$ ) mapping of $\mathrm{P}, \mathrm{h}$ ) mapping $\mathrm{of} \mathrm{Cl}, \mathrm{i}$ ) mapping of $\mathrm{Na}$ and $\mathrm{j}$ ) mapping of $\mathrm{O}$.

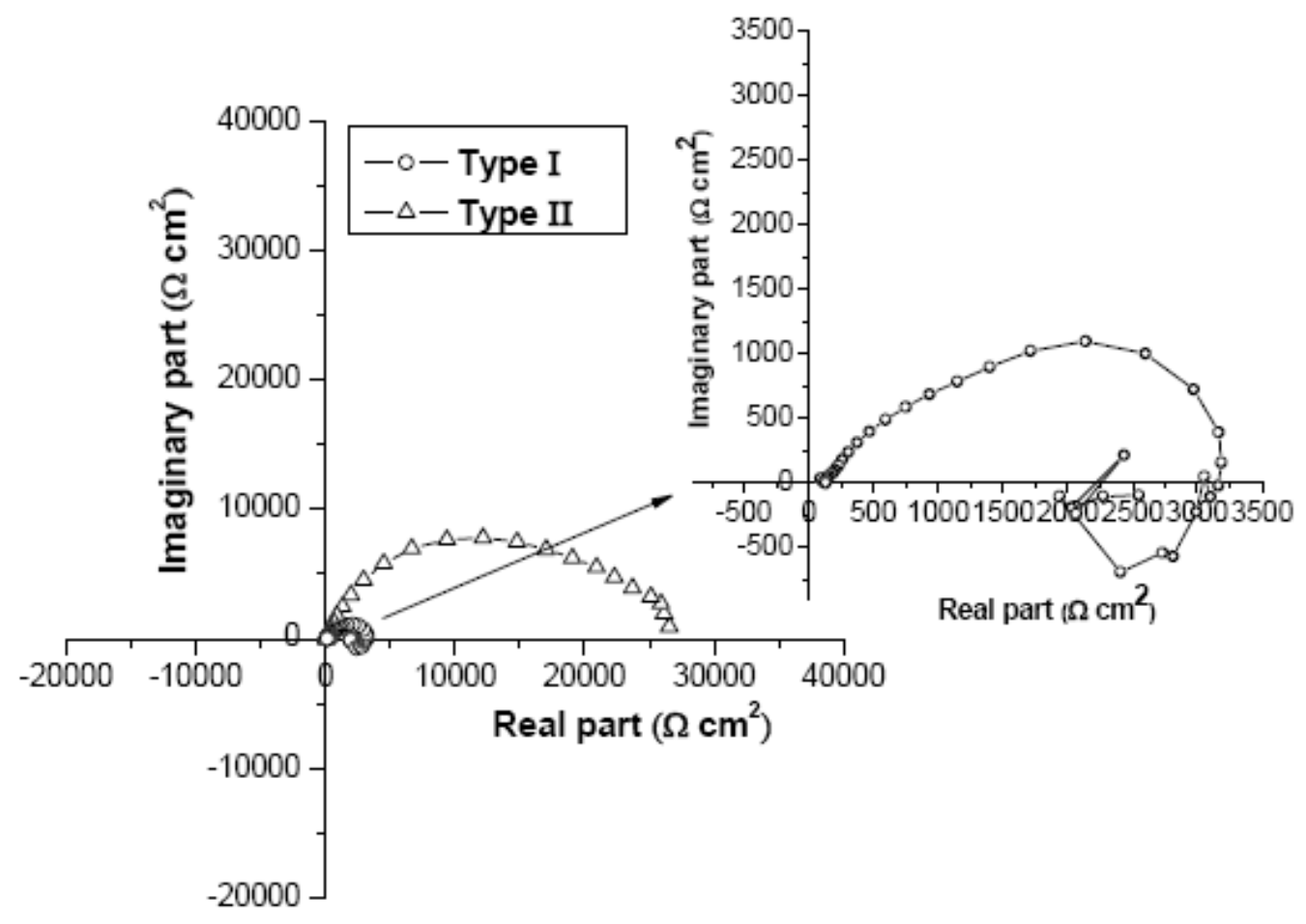

Figure 8. Nyquist plots of Type I and Type II AZ31 alloys in PBS solution for six days immersion time 
(a)

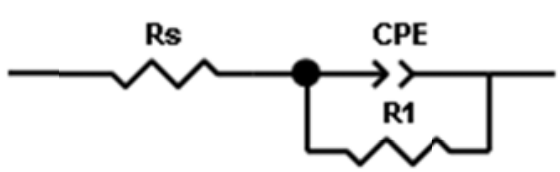

(b)

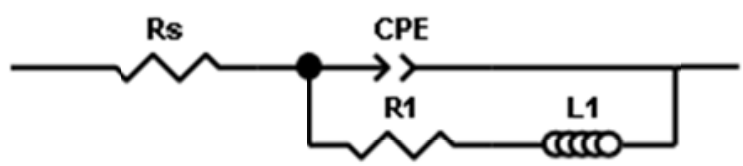

Figure 9. Equivalent circuits. Rs is the electrolyte resistance; CPE1 is the oxide film capacitance and the double layer capacitance; R1 is the charge transfer resistance and the oxide film resistance; $\mathrm{L} 1$ is the inductive element.

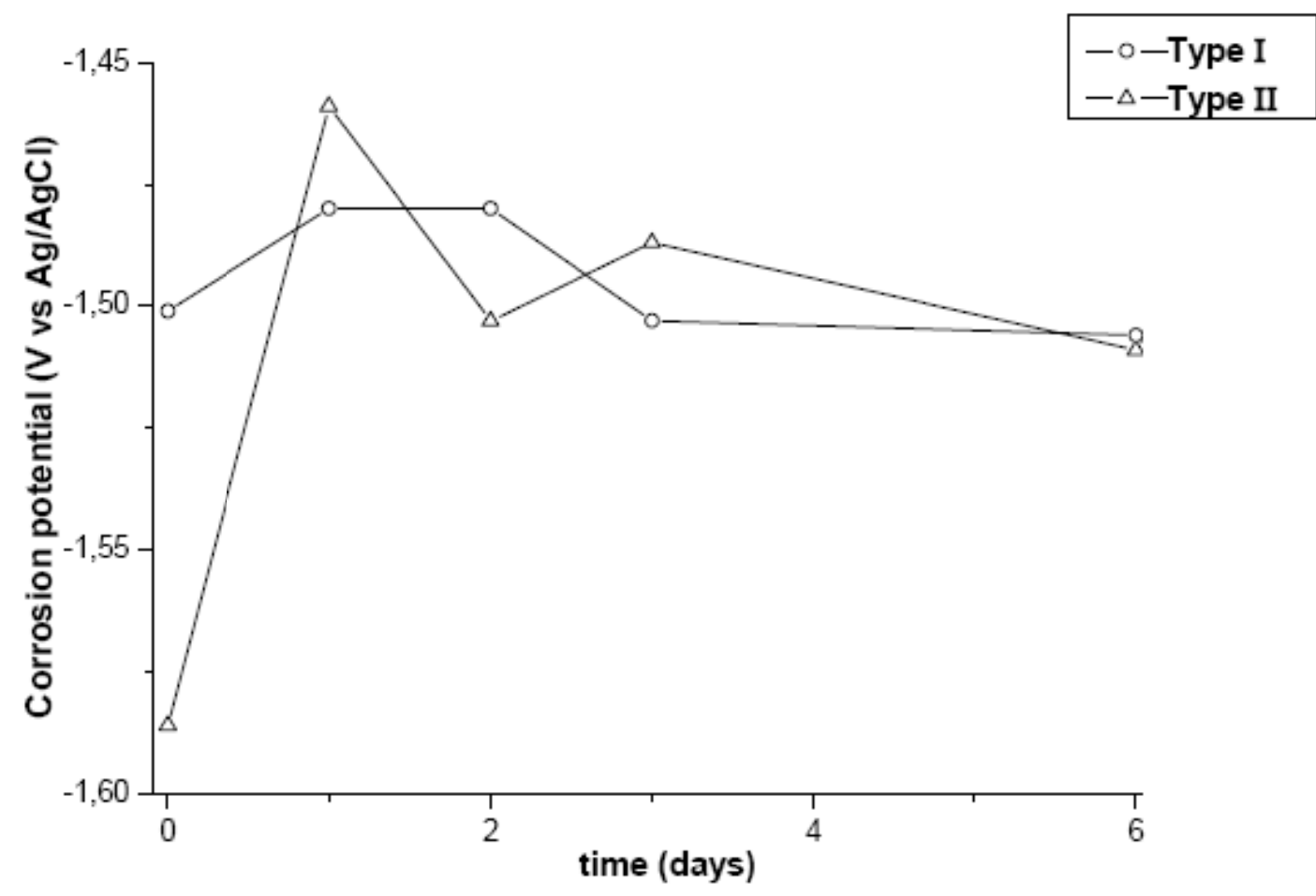

Figure 10. Corrosion potential, Ecorr, of Type I and Type II AZ31 alloy in PBS over immersion time. 


\begin{tabular}{|c|c|c|c|c|c|c|}
\hline MATERIAL & MEDIUM & TIME & CONDITION & $\begin{array}{l}\text { Rs } \\
(\Omega)\end{array}$ & $\begin{array}{c}\mathrm{C} \\
\left(\mu \mathrm{F} / \mathrm{cm}^{2}\right. \\
\mathrm{CPE})\end{array}$ & $\begin{array}{c}\mathrm{R} 1 \\
\left(\Omega \mathrm{cm}^{2}\right)\end{array}$ \\
\hline \multirow{8}{*}{ Type I } & \multirow{4}{*}{$\mathrm{NaCl}$} & \multirow{2}{*}{2 hours } & Experimental & 109 & 7.8 & 1268 \\
\hline & & & Fitting & 109 & 10.8 & 1211 \\
\hline & & \multirow{2}{*}{6 days } & Experimental & 135 & 10.0 & 3838 \\
\hline & & & Fitting & 130 & 21.2 & 4021 \\
\hline & \multirow{4}{*}{ PBS } & \multirow{2}{*}{2 hours } & Experimental & 113 & 12.6 & 885 \\
\hline & & & Fitting & 113 & 18.8 & 922 \\
\hline & & \multirow{2}{*}{6 days } & Experimental & 261 & 1.6 & 2230 \\
\hline & & & Fitting & 268 & 34.0 & 2847 \\
\hline \multirow{8}{*}{ Type II } & \multirow{4}{*}{$\mathrm{NaCl}$} & \multirow{2}{*}{2 hours } & Experimental & 150 & 7.6 & 3860 \\
\hline & & & Fitting & 148 & 9.2 & 3706 \\
\hline & & \multirow{2}{*}{6 days } & Experimental & 166 & 14.4 & 12400 \\
\hline & & & Fitting & 166 & 24.0 & 13330 \\
\hline & \multirow{4}{*}{ PBS } & \multirow{2}{*}{2 hours } & Experimental & 113 & 11.4 & 2139 \\
\hline & & & Fitting & 114 & 21.2 & 2299 \\
\hline & & \multirow{2}{*}{6 days } & Experimental & 179 & 14.3 & 22558 \\
\hline & & & Fitting & 171 & 19.6 & 22959 \\
\hline
\end{tabular}

Table I. Results obtained from the impedance diagrams for the Type I and II AZ31 alloys in $\mathrm{NaCl}$ and PBS over immersion time and fitted data of the equivalents circuits of Figure 9. 